\title{
Origin and ecological selection of core and food-specific bacterial communities associated with meat and seafood spoilage
}

\author{
Stéphane Chaillou ${ }^{1,2}$, Aurélie Chaulot-Talmon ${ }^{1,2}$, Hélène Caekebeke ${ }^{3}$, Mireille Cardinal ${ }^{4}$, \\ Souad Christieans ${ }^{5}$, Catherine Denis ${ }^{6}$, Marie Hélène Desmonts ${ }^{7}$, Xavier Dousset ${ }^{8,9}$, \\ Carole Feurer ${ }^{10}$, Erwann Hamon ${ }^{7}$, Jean-Jacques Joffraud ${ }^{4}$, Stéphanie La Carbona ${ }^{6}$, \\ Françoise Leroi ${ }^{4}$, Sabine Leroy ${ }^{11}$, Sylvie Lorre ${ }^{12}$, Sabrina Macé ${ }^{8,9}$, Marie-France Pilet ${ }^{8,9}$, \\ Hervé Prévost ${ }^{8,9}$, Marina Rivollier ${ }^{5}$, Dephine Roux ${ }^{3}$, Régine Talon ${ }^{11}$, Monique Zagorec ${ }^{8,9}$ \\ and Marie-Christine Champomier-Vergès ${ }^{1,2}$ \\ ${ }^{1}$ INRA, UMR1319 Micalis, Lactic Acid Bacteria \& Meat Microbial Ecosystems Laboratory, Paris, France; \\ ${ }^{2}$ AgroParisTech, UMR Micalis, Paris, France; ${ }^{3}$ Plate-Forme d'Innovations Nouvelles Vagues, Boulogne- \\ sur-mer, France; ${ }^{4}$ Ifremer, Nantes, France; ${ }^{5}$ ADIV, Clermont-Ferrand, France; ${ }^{6}$ ACTALIA, Villers Bocage, \\ France; ${ }^{7}$ Aérial, Strasbourg, France; ${ }^{8}$ INRA, UMR1014 Secalim, Nantes, France; ${ }^{9}$ LUNAM Université, Oniris, \\ Nantes, France; ${ }^{10}$ IFIP, Paris, France; ${ }^{11}$ INRA, UR454 Microbiologie, Saint-Genès-Champanelle, France and \\ ${ }^{12}$ Biocéane, Nantes, France
}

\begin{abstract}
The microbial spoilage of meat and seafood products with short shelf lives is responsible for a significant amount of food waste. Food spoilage is a very heterogeneous process, involving the growth of various, poorly characterized bacterial communities. In this study, we conducted 16S ribosomal RNA gene pyrosequencing on $\mathbf{1 6 0}$ samples of fresh and spoiled foods to comparatively explore the bacterial communities associated with four meat products and four seafood products that are among the most consumed food items in Europe. We show that fresh products are contaminated in part by a microbiota similar to that found on the skin and in the gut of animals. However, this animal-derived microbiota was less prevalent and less abundant than a core microbiota, psychrotrophic in nature, mainly originated from the environment (water reservoirs). We clearly show that this core community found on meat and seafood products is the main reservoir of spoilage bacteria. We also show that storage conditions exert strong selective pressure on the initial microbiota: alpha diversity in fresh samples was $189 \pm 58$ operational taxonomic units (OTUs) but dropped to $27 \pm 12$ OTUs in spoiled samples. The OTU assemblage associated with spoilage was shaped by low storage temperatures, packaging and the nutritional value of the food matrix itself. These factors presumably act in tandem without any hierarchical pattern. Most notably, we were also able to identify putative new clades of dominant, previously undescribed bacteria occurring on spoiled seafood, a finding that emphasizes the importance of using culture-independent methods when studying food microbiota.
\end{abstract}

The ISME Journal (2015) 9, 1105-1118; doi:10.1038/ismej.2014.202; published online 21 October 2014

\section{Introduction}

Packaged meat and fish products are highly perishable. These food items of animal origin are subject to natural contamination by many bacterial species, as they provide a nutrient-rich environment with high water activity and a near-neutral $\mathrm{pH}$ that is optimal for growth. Spoilage is due to the uncontrolled growth and subsequent various metabolic activities

Correspondence: S Chaillou, INRA, UMR1319 Micalis, Lactic Acid Bacteria \& Meat Microbial Ecosystems Laboratory, Domaine de Vilvert, Bâtiment 526, Paris F-78350, France.

E-mail: stephane.chaillou@jouy.inra.fr

Received 24 March 2014; revised 10 July 2014; accepted 3 September 2014; published online 21 October 2014 of the dominant microbiota found on these foods (Gram and Dalgaard, 2002; Doulgeraki et al., 2012). Product spoilage is problematic both because it renders food unfit for human consumption and because it results in significant economic losses when products must be removed from supermarket shelves. It is commonly assumed that meat and seafood microbiota originate from the processed animal's skin or intestines and that contamination occurs during the successive steps of food processing (Labadie, 1999; Nychas et al., 2008). As a result, different strategies (for example, low storage temperatures, modified-atmosphere packaging and curing protocols) are applied in an attempt to curb microbial growth. To date, however, we still understand very little about the roles played by the broad 
spectrum of species involved in spoilage. Many studies showed that bacteria are the predominant spoilage micro-organisms on meat and seafood, as various assortments of dominant species from Lactobacillales, Bacillales, Enterobacterales, Pseudomonadales and Vibrionales, easily reach a population level of $8 \log _{10}$ (c.f.u.g ${ }^{-1}$ ). (see Ercolini et al., 2006; Joffraud et al., 2006; Jaffrès et al., 2011; Jiang et al., 2011; De Filippis et al., 2013; Macé et al., 2013; Olsson et al., 2003; Olofsson et al., 2007; Reynisson et al., 2009; Nieminen et al., 2012; Sade et al., 2013 for recent research). Yeasts and molds are also present but these micro-organisms are rarely monitored as spoilers because they usually form a subdominant microbiota (ca. $4 \log _{10}$ (c.f.u.g ${ }^{-1}$ )) which is detectable mainly after long shelf-life and when meat and seafood are stored aerobically or at low $A_{\mathrm{w}}$ (Leroi et al., 1998; Ismail et al., 2000; Argyri et al., 2001; Patsias et al., 2006; Nielsen et al., 2008; Boziaris et al., 2012), these conditions being now barely used in EU food industry. Although the role of bacterial growth in meat and seafood spoilage is well-established, it remains difficult to understand the factors underlying the diversity of spoilage bacterial communities in a comprehensive way given the wide variability of the products and processes analyzed. Indeed, it is poorly understood how these food products promote the growth of particular sets of species and how members of these microbial communities compete or interact. In particular, large sampling surveys have not yet been used to clearly establish how the bacterial communities living in these food products are structured or how selection takes place once initial contamination has occurred.

The present study aimed to provide a more integrated view of the bacterial communities associated with meat and seafood spoilage at a heretoforeunseen scale. To this end, four different meat products and four different seafood products were sampled: ground beef, ground veal, poultry sausage, diced bacon, smoked salmon, cooked peeled shrimp, salmon fillet and cod fillet. These products were chosen using three main criteria: (1) they have some of the highest consumption rates in Europe and thus their spoilage is a critical economic problem (Kanerva, 2013; EUFOMA, 2014); (2) they are made from six different animals (two mammals, one bird, two fish species and one crustacean), which makes it possible to conduct a $\beta$-diversity analysis that includes the origin of the contaminating microbiota; and (3) some of them were similar in nature (ground beef versus ground veal or smoked salmon versus salmon fillet), which meant they could be used in comparative analyses or, alternatively, to assess the role of processing and packaging in shaping spoilage microbiota. All the food products used in this study were packaged and stored according to standard methods commonly used by food companies to establish the product's use-by-date, which means that our results may prove useful to the food industry.
To characterize bacterial communities, we pyrosequenced the $\mathrm{V} 1-\mathrm{V} 3$ region of the $16 \mathrm{~S}$ ribosomal RNA gene. We felt it was important to describe bacterial diversity at the species level whenever possible, as spoilage may be species dependent. Furthermore, we hypothesized that extensive sampling (10 batches of each food type) would help us overcome the challenge, which may be posed by intersample variability in food microbiota.

\section{Materials and methods}

\section{Sample collection and microbial analysis}

For each food item (Table 1) 10 batches were analyzed at two storage times (20 samples). We used for each batch four to six sets of five individual packages. One set was used for the initial analysis ( $T_{0}$ sample), while the others were kept in storage in accordance with the French standard food aging test (NF-V01-003, 2010). In this standard test, food is kept at $4{ }^{\circ} \mathrm{C}$ for the first third of a period leading up to the use-by date; it is then placed at $8{ }^{\circ} \mathrm{C}$. On the use-by date, one set was assessed for spoilage by visual and sensorial analysis (Matamoros et al., 2009; Macé et al., 2013). If the set was spoiled, it was included in the analysis as $T_{S}$ sample; if not, the remaining sets were stored for several more days until spoilage occurred. For each food batch, the five individual packages that made up each set $\left(T_{0}\right.$ or $\left.T_{\mathrm{s}}\right)$ were blended together for microbial analysis and DNA extraction, representing one homogenized sample (one $T_{0}$ or one $T_{\mathrm{s}}$ sample). Thus, a total 160 homogenized samples were produced (8 food items $\times 10$ homogenized samples for $T_{0}$ and 8 food items $\times 10$ homogenized samples for $T_{\mathrm{S}}$ ). Total viable counts were determined after the bacteria were incubated in aerobic conditions; incubation lasted for $3-5$ days at $30^{\circ} \mathrm{C}$ on plate count agar in the case of meat samples and 7-10 days at $15^{\circ} \mathrm{C}$ on Long and Hammer agar $(1 \% \mathrm{NaCl})$ in the case of seafood samples (Broekaert et al., 2011).

DNA extraction, PCR and barcoded pyrosequencing Twenty grams of food were mixed with $80 \mathrm{ml}$ saline buffer (tryptone $1 \mathrm{gl}^{-1}, \mathrm{NaCl} 8.5 \mathrm{gl}^{-1}$ and $1 \%$ Tween $80)$ and then homogenized $(2 \times 2 \mathrm{~min}$; Lab Blender 400, Interscience, Saint Nom, France). We obtained the bacterial cell pellets by first using a NucleoSpin Plant II kit (Macherey-Nagel, Hoerdt, France) to filter 9-ml aliquots of homogenate and then subjecting the resulting samples to $10 \mathrm{~min}$ of centrifugation at $10000 \mathrm{~g}$. This technique captured in the column DNA from both non-viable (lysed) microbial cells and contaminant eukaryotic DNA from the food matrix, while non-lysed bacterial cells formed a pellet. To lyse the remaining bacterial cells, 100-mg samples were vigorously shaken with glass beads (30 s of vortexing), then exposed to lysozyme $\left(20 \mathrm{mg} \mathrm{ml}^{-1}\right)$ and mutanolysin (12 U) for $60 \mathrm{~min}$ at 


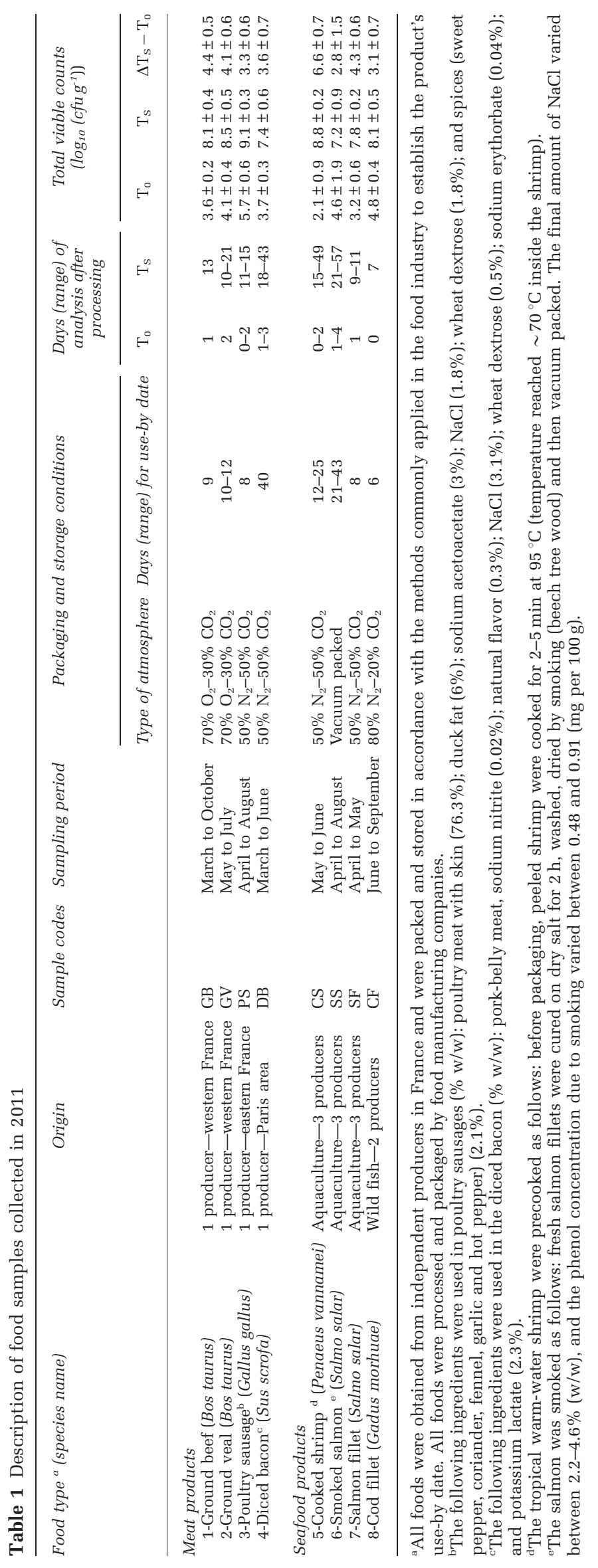


$37^{\circ} \mathrm{C}$. Total microbial DNA was extracted and purified using a DNAeasy Blood and Tissue kit (Qiagen, Courtaboeuf, France) or a Nucleospin Tissue kit (Macherey-Nagel) in accordance with the manufacturer's instructions; the resulting samples were then stored at $-20^{\circ} \mathrm{C}$. Approximately $10 \mathrm{ng}$ DNA was used as the PCR template, and PCR bias was minimized with the following cycling conditions: a temperature gradient $\left(60-0.5^{\circ} \mathrm{C}\right.$ per cycle) and 25 cycles, as described in the study by Barott et al. (2011). Amplification of the 16S rDNA V1-V3 region was performed using $27 \mathrm{~F}$ and $534 \mathrm{R}$ primers (Lane, 1991) fused to sample-specific multiplex identifiers. Three PCR reactions per sample were performed, and the amplified DNA was purified with a QIAquick kit (Qiagen); checked for size, quality and quantity on a DNA7500 chip (Agilent Technologies, Paris, France); then pooled in equimolar quantities. For each PCR pool, two sequencing replicates (A-forward and B-reverse sides) were performed using the 454 GS-FLX Titanium platform (Eurofins, Ebersberg, Germany) making up 320 independent sequencing reactions for the 160 samples. The scale and design of the 454-pyrosequencing runs are described in Supplementary File S1.

\section{Quality filtering, definition of OTUs and taxonomic assignment}

Quality filtering (QF) of raw sequences was performed using both the RDP pipeline (Cole et al., 2009) and the PRINSEQ command of SAMTOOLS (Li et al., 2009); it removed reads shorter than 250 nucleotides, reads with average quality scores lower than 25 , reads that were more than $2 \%$ homopolymers, reads with ambiguous ' $N$ ' nucleotides and reads with mismatches in their primer sequences. Filtered reads were further trimmed at the $3^{\prime}$ end using a quality cutoff of $>20$. The QF reads have been deposited at the European Nucleotide Archive (ENA) under the project accession number PRJEB4975. To facilitate taxonomic assignment, we adapted a pipeline to identify operational taxonomic units (OTUs) at the species level and to construct a distance matrix that allowed us to compare the relative abundance of OTUs among food types (Supplementary File S2). Briefly, QF reads from the complete data set were binned into OTUs using a 97\% identity threshold and employing CD-HIT (Li and Godzik, 2006); this was followed by the selection of a representative sequence from each OTU (Caporaso et al., 2010). These OTUs were further subjected to quality control (see Supplementary File S2), and chimeras were detected using DECIPHER (Wright et al., 2011). For each OTU, taxonomy was inferred by aligning the representative sequences to relevant sequences in several databases. First, a non-redundant (nr99) version of the LTPs106 reference database of typestrain SSU ribosomal RNA (Munoz et al., 2011) (see details in Supplementary File S2) was used to assign annotation at the species level or at the level of closely related species clusters. Other online databases were then used for validation. These included SILVA (Quast et al., 2012), using a SINA aligner and a 98\% identity threshold (Pruesse et al., 2012); the RDP classifier (Cole et al., 2009), using the first level to reach an $80 \%$ confidence threshold; and the EzTaxon-e uncultured species database (Kim et al., 2012), using a BLAST identity threshold of $97 \%$. OTUs affiliated with chloroplasts and mitochondria were removed. Overall, 508 OTUs (ENA accession HG818119 to HG818626) were annotated and used in our analyses of microbial communities. The quantification of the OTUs present in each sample was performed by directly aligning the corresponding QF reads to the 508 annotated OTUs to construct an abundance matrix (Supplementary File S3).

\section{Sequencing replicates, quantitative and qualitative} controls

We performed extensive quality control to verify reproducibility across sequencing runs. We checked for potential bias in DNA extraction, the reproducibility of technical replicates between two emulsion PCRs, and the reproducibility of forward-A versus reverse-B data; in some cases, we also performed comparisons using temporal temperature gel electrophoresis analysis. These methodologies are described in Supplementary File S1.

\section{Comparative and statistical analysis of diversity}

To compare the relative abundance of OTUs, the number of QF reads were normalized. Read counts (sum of both technical replicates for each sample) were divided by a sample-specific scaling factor $\left(\hat{s_{\mathrm{j}}}=N_{\mathrm{j}} / m_{\mathrm{e}}\right)$, where $\hat{s_{\mathrm{j}}}$ is normalization factor associated with sample $\mathrm{j} ; N_{\mathrm{j}}$ is the number of total reads in sample $\mathrm{j}$ and $m_{\mathrm{e}}$ is the median value of total reads for the $n=160$ samples of the data set. The Chao1 nonparametric estimator of minimum richness (Chao, 1984) was calculated using non-normalized counts. Fisher's exact tests were used to compare the normalized counts between each food type. The Chao1 estimator and the values of the Fisher's tests were calculated using the VEGAN package (Dixon, 2003) in $R$ version 2.15.1 ( $R$ Development Core Team, 2010). Principle coordinates analysis and average linkage hierarchical clustering using weighted or unweighted UNIFRAC distances were conducted using the FAST UNIFRAC server (Hamady et al., 2010). Phylogenetic trees were inferred in SEAVIEW 4.0 (Gouy et al., 2010) using a PhyML-based maximum likelihood algorithm (Guindon et al., 2010) and the HKY85 model (GTR model resulted in similar UNIFRAC results). OTU prevalence at $T_{0}$ was estimated using two parameters: (1) OTU frequency within each food type (that is, how many times an OTU occurred across 
the 10 samples of a given food type) and (2) The specificity of OTU prevalence in each food type in comparison with the whole data set (that is, number of positive samples within a given food type divided by the number of positive samples across the full 80sample $T_{0}$ data set). To estimate the support for the OTU prevalence clustering patterns found in fresh samples, approximately unbiased $P$-values were calculated using the PVCLUST package in $\mathrm{R}$ (Susuki and Shimodaira, 2006), with 10000 bootstrap resamplings. To reveal the overlap in OTU communities among spoiled food samples, the SAMMON function in the MASS package in $\mathrm{R}$ (Sammon, 1969; Venables and Ripley, 2002) was used to map the values of a Jaccard dissimilarity matrix based on co-occurence; 50 iterations were used.

\section{Ecology and origin of OTUs}

For each OTU that we were able to assign to a cultured species, we selected one or two articles in PubMed database that described its isolation and/or most common environmental habitat to infer details about its origin and ecology. For uncultured species described from environmental samples (metagenomic surveys), we examined the relevant publication. Individual OTUs could have more than one environmental origin (for example, Flavobacterium spp. are often found in both water and soil). The origins of OTU clusters were estimated by counting the occurrences of all the OTUs in a given cluster in a certain habitat type and determining the average proportion of occurrence in each habitat type. This strategy was used to provide a generalized characterization of the possible origins of the contaminating microbiota identified in our study. For the OTUs belonging to core communities, the title and abstract of the relevant references were also extracted and filtered to obtain several relevant sets of words (for example, removal of species name, verbs and molecular biology terms). Word occurrence in the pool of filtered texts was then analyzed using Wordle (http://wordle.net; default settings; see Supplementary File S5) to reveal patterns in OTU ecology.

\section{Results and Discussion}

Study design

Fresh food products were collected from commercial suppliers over several months in 2011 (Table 1). For each food type, we assessed its intrinsic variability by analyzing 10 different samples. Fresh samples $\left(T_{0}\right)$ were analyzed as soon as possible after collection, and spoiled samples $\left(T_{\mathrm{S}}\right)$ were analyzed at time points beyond the use-by date, once spoilage had been clearly established. Cod and salmon fillets spoiled most rapidly (in 7-9 days), whereas products that had undergone some sort of prepackaging treatment (smoked salmon, cooked shrimp and diced bacon) had longer shelf-life (18-57 days). The concentration of total viable populations of cultivable micro-organisms, expressed as $\log _{10}$ (c.f.u. ${ }^{-1}$ ), were relatively constant across samples of the same food type. Between $T_{0}$ and $T_{S}$, these concentrations increased from an average of $3.9 \pm 1.3$ to an average of $7.9 \pm 0.8$; this represents an increase of $4 \log _{10}$ (c.f.u. g-1), irrespective of the time to spoilage. As already shown in previous studies (Mejlholm et al., 2005; Jaffrès et al., 2009) and perhaps because they are cooked prior to packaging, the shrimp yielded low number of viable populations at $T_{0}$. However, they still reached an average of $8.8 \pm 0.2$ at $T_{\mathrm{S}}$ (and hence demonstrated the greatest increase: $6 \log _{10}$ (c.f.u. g $\left.{ }^{-1}\right)$ ).

Bacterial richness varied in fresh $\left(T_{0}\right)$ and spoiled products $\left(T_{S}\right)$

We analyzed a total of 2435219 bacterial $16 \mathrm{~S}$ ribosomal RNA sequences (median value of $14980 \pm 5050$ per sample) obtained from 160 samples $\left(T_{0}+T_{S}\right)$. This sequencing depth ( $\sim 4 \log$ scale) ensured that coverage was adequate for assessing the richness present in $T_{0}$ and $T_{S}$ populations. At $T_{0}$ (Figure 1a), an average of $189 \pm 58$ species-level OTUs (97\% identity threshold; Supplementary File S2) were recovered per sample. Notably, significant divergence from this average was observed in diced bacon, which had higher levels of species richness (260 \pm 45 OTUs), and in smoked salmon, which had lower levels of species richness (123 \pm 36 OTUs). For smoked salmon, we attribute these results to the salting/washing process and the probable bactericidal effects of the smoking process. We also expected OTU richness to be lower in fresh shrimp, as the precooking had a clear effect on the size of the $T_{0}$ cultivable population (Table 1). However, OTU richness in these samples was, surprisingly, no different than that in other food samples. As the total number of OTUs detected at $T_{0}$ was only 508, there was significant overlap among the microbiota of the different food products. Indeed, this value was only ca. 2.5 times that of the average number of OTUs in each food product type, an observation that suggested that core communities were present on all or most food products. In most cases, the predicted number of OTUs (estimated by the Chao1 statistic based on rare ribotypes-singletons and doubletons) did not differ significantly from the average number of observed OTUs, which indicates that sequencing efforts conducted on fresh samples were likely adequate. However, we did observe a significant difference in the predicted and observed numbers of OTUs for $T_{0}$ poultry sausage samples $(P<0.01$, twotailed $t$-test), a result that we attributed to $58 \%$ of the $T_{0}$ sequences in these samples being assigned to chloroplasts (Supplementary File S1). As chloroplast sequences were likely derived from the sausage spices, they were removed from the 

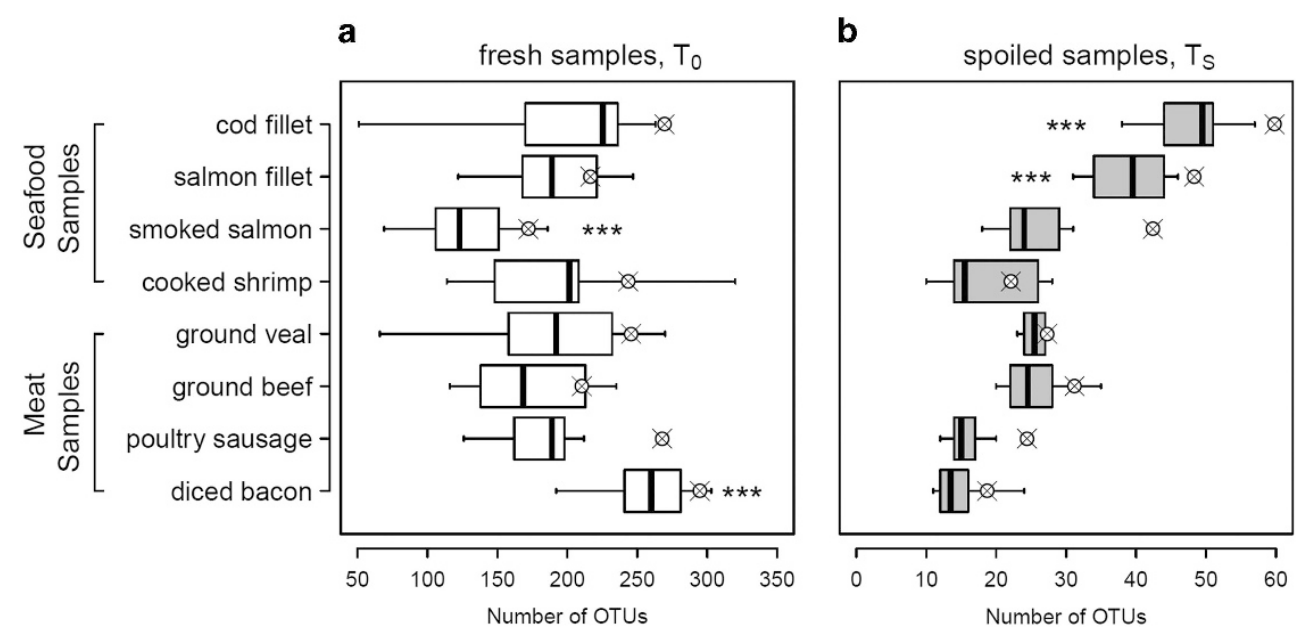

Figure 1 Bacterial richness in meat and seafood products. The box plot shows the number of OTUs identified in different food products at $T_{0}(\mathbf{a})$ and $T_{\mathrm{S}}(\mathbf{b})$. The boxes represent the interquartile range between the first and third quartiles and the vertical black line inside the box is the median obtained from the 10 samples analyzed per food product. The striped circles represent the average value of the Chao1 estimator (Chao, 1984) calculated from each set of 10 samples. The presence of stars indicates that samples deviated significantly from the average $(P<0.01$, two-tailed $t$-test $)$.

analysis, potentially resulting in shallower sequencing coverage. OTU richness was markedly lower in spoiled products; an average of $27 \pm 12$ OTUs were present per sample (Figure 1b), and a total of 113 OTUs were identified at $T_{\mathrm{S}}$. A considerable fraction of the overall richness was derived from salmon and cod fillets; they spoiled more quickly (Table 1) and had significantly higher levels of richness ( $40 \pm 5$ OTUs and $48 \pm 6$ OTUs, respectively) than did other food types. It therefore appears that between $T_{0}$ and $T_{\mathrm{S}}$ in these two foods, the selective pressures (exerted by the combination of changes in storage atmospheres and availability of nutrients) were weaker, as there was only a ca. fourfold reduction in richness. In contrast, selective pressures appeared to be stronger in diced bacon, which demonstrated $\sim 20$-fold reduction in richness.

\section{Microbial communities found in fresh meat and} seafood differ in their origins and ecologies

The analysis of microbial $\beta$-diversity using unweighted UNIFRAC distances showed that $T_{0}$ sample clustering was strongly associated with the existence of distinct OTU communities (Figure 2). These communities were composed of two types of OTUs: about half $(42.3 \pm 7.5 \%)$ were product specific, while the other half $(57.7 \pm 7.5 \%)$ were part of a core community (on meat, on seafood, or in general, that is, OTUs prevalent across all food types and found in $>50 \%$ of the samples of each food type). As illustrated in Figure 3a, Firmicutes and Actinobacteria were most prevalent on meat products and formed a large part of the core meat community, whereas Proteobacteria and Bacteroidetes were most common on seafood and were a large part of the core seafood community. This difference in community composition was strongly correlated with the inferred origins of these OTUs and to the ecological and physiological features associated with the core communities (Figure 3b; Supplementary File S5).

Seafood OTUs are a mixture of environmental and fish gut microbiota

The core seafood community (59 OTUs) was mainly composed of water-borne bacteria assigned to the genera Flavobacterium, Chryseobacterium and Photobacterium. However, we also observed notable differences across seafood-specific OTU clusters. For example, the cod-fillet-specific cluster (57 OTUs) differed from the salmon-fillet-specific cluster because it contained more bacteria assigned to the genera Shewanella, Psychrobacter and Arthrobacter frequently isolated from seawater (Fredrikson et al., 2008), as well as several uncharacterized OTUs in the phylum Fusobacteria that our SILVA analysis assigned to the putative Hados.Sed.Eubac.3 family. Notably, this family comprises several species of symbiotic uncultured bacteria found in fish guts (Roeselers et al., 2011). In contrast, the salmon-fillet cluster (34 OTUs) contained more OTUs assigned to genera commonly found in freshwater sediments or wastewater (Cloacibacterium, Comamonadaceae and Rhizobiales) (Ye et al., 2012). However, many of these species are also members of the microbiota found in fish guts (Wong and Rawls, 2012). Interestingly, the differences in bacterial community composition between fresh samples of cod and salmon mirror those observed in the guts of marine versus freshwater fishes (Sullam et al., 2012), whose intestinal microbes are influenced by feeding behavior (for example, carnivory versus omnivory) and by environmental water during early life development (Hansen and Olafsen, 1999). Our 


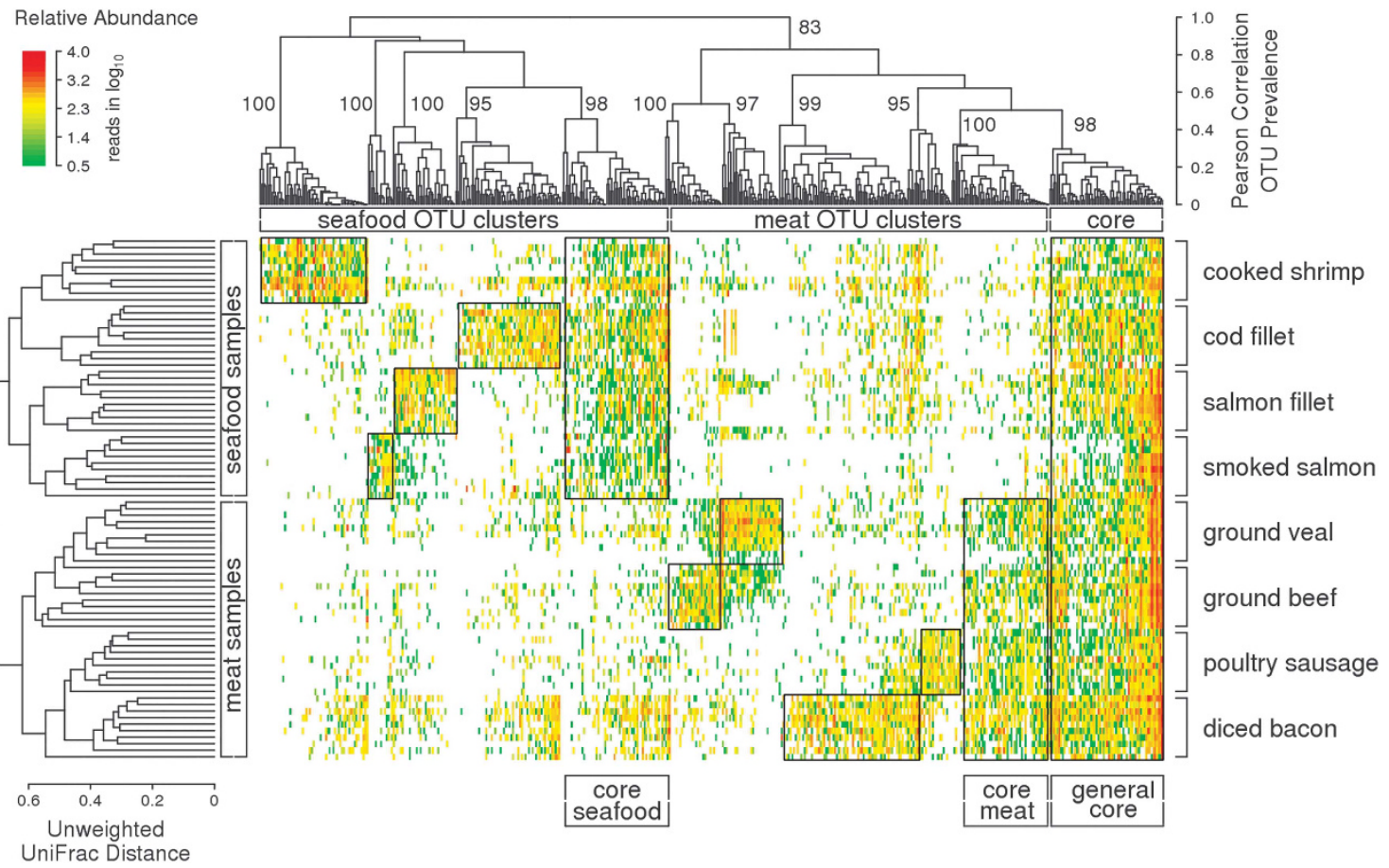

Figure 2 Heat map showing the relationship between $T_{0}$ sample UNIFRAC clustering and OTU prevalence. The tree on the left side of the figure depicts the unsupervised hierarchical clustering of the $80 T_{0}$ samples using the average linkage of unweighted UniFrac distances. The two main UniFrac clusters correspond to meat versus seafood products and the sub-branches are the 10 samples of each type of food product. The tree at the top of the figure depicts the unsupervised hierarchical clustering of the 508 OTUs in the $T_{0}$ data set using the average linkage of the correlation distances calculated from the OTU prevalence values. The approximately unbiased $P$-values were calculated using multiscale bootstrap resampling in PVCLUST and are given for each OTU prevalence cluster (boxes on the heat map). The identities of these OTU clusters are provided at the bottom of the tree; the identities of the core community clusters are identified at the bottom of the figure. A complete list of the OTUs, organized according to prevalence clusters and taxonomic assignment, can also be found in Supplementary File S4.
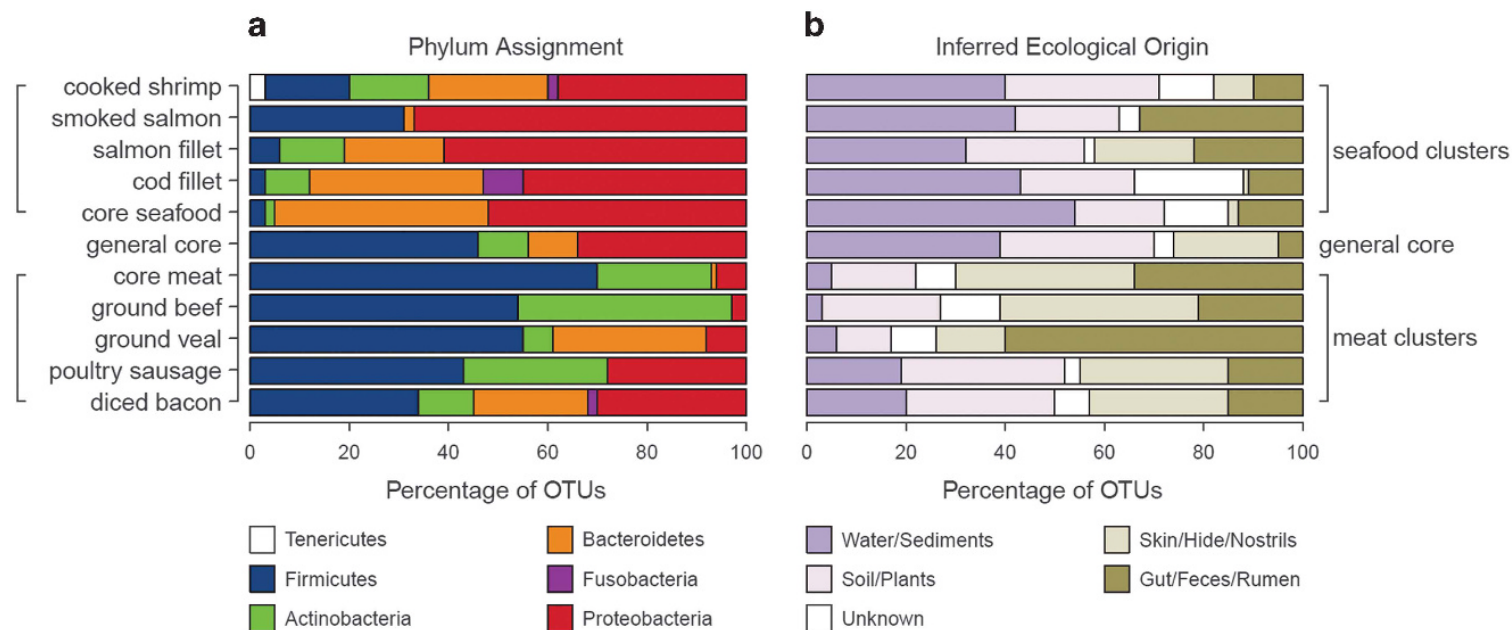

Figure 3 Inferred taxonomy and ecological origin of $T_{0}$ OTU prevalence clusters. Barplots showing (a) the phylum-level distribution of the OTUs within each prevalence cluster observed at $T_{0}$ and (b) the distribution of the inferred ecological origins of the OTUs. Ecological origins were inferred for each OTU attributed to a known species and for which a reference was available. Details about this process can be found in the Methods section and in Supplementary File S4. The white bar in b indicates OTUs without assignments at the 97\% identity threshold in cultured (LTPs106) and uncultured (EZtaxon-e) databases.

results corroborate these views, because Atlantic salmon migrate between both type of waters, and coastal seawater farms have inherent probability of wastewater and sediment contaminations.
A comparison of smoked salmon to fresh salmon revealed that OTUs originating from fish guts are strongly affected by the washing/smoking process (detail of this process can be found in footnote of 
Table 1), whereas the core OTUs that come from environmental reservoirs appear to be more resistant. Furthermore, smoked salmon contained 14 unique OTUs not found in salmon fillet samples, indicating likely a post contamination during the washing/smoking. These OTUs mostly belong to Photobacterium, a water-borne genus commonly associated with seafood spoilage (Dalgaard, 1995; Gram and Huss, 1996; Leroi et al., 1998; Joffraud et al., 2006; Hovda et al, 2007; Olofsson et al., 2007; Reynisson et al., 2009; Macé et al., 2013). The cooked shrimp cluster (59 OTUs) also contained two distinct groups: (1) OTUs affiliated to well-known thermal resistant bacteria (Exiguobacterium, Rhodobacteriaceae and Chromatiaceae) from geothermal deep sea sediments (Rodrigues et al., 2008; Broekaert et al., 2013) that may have been selected for by the precooking process; (2) OTUs linked with putative uncultured endosymbionts in the phyla Tenericutes and Proteobacteria (Kostanjsek et al., 2007; Robidart et al., 2008; Nechitaylo et al., 2009). The most abundant OTU (EBP1918) recovered from cooked shrimp was assigned to the putative CK-1C419 phylum in SILVA, a taxon that comprises several uncultured endosymbiotic bacteria of ants (Russell et al., 2009; Funaro et al., 2011). As shrimp, like other crustaceans, probably host endosymbiotic bacteria (Guri et al., 2012), this OTU may represent an undescribed crustacean endosymbiont. The presence in the $T_{0}$ shrimp abundant microbiota (ca. relative abundance $>2 \log _{10}$ reads above most OTUs) of extremophiles and of putative endosymbionts, most likely uncultivable using conventional plating media, could be the reason why $T_{0}$ cooked shrimp samples have low counts of viable population in comparison with other products (Table 1).

\section{Meat OTUs reveal specific contamination by animal microbiota}

In contrast to the seafood-specific OTUs, meatspecific OTUs (55 OTUs) were strongly affiliated with the microbiota of terrestrial animals, including bacteria found on skin, nostrils (Corynebacterium and Propionibacterium) (Lemon et al., 2010; Schommer and Gallo, 2013) and in the gastrointestinal tract (Lactobacillus, Enterococcus and Clostridium). Similarly, beef- and veal-specific OTUs (60 in total) were revealed to be members of the rumen microbiota (Jami et al., 2013). We found that Corynebacterium OTUs were particularly prevalent on beef, whereas Prevotella OTUs were more common on veal, which suggests that beef and veal are more frequently contaminated by skin and rumen bacteria, respectively. There were relatively fewer poultry-sausage-specific OTUs (23 altogether), likely because of shallower sequencing coverage. However, the poultry samples appeared to be contaminated with bacteria typically found in poultry litter ( $\mathrm{Lu}$ et al., 2003) or in bird feces (Baele et al., 2003). In fact, only the diced-bacon- specific cluster (72 OTUs) contained bacteria of mixed origins, including those (for example Streptococcus) commonly found at a high carriage levels in pigs (Lun et al., 2007; Lu et al., 2013) as well as those typically found in environmental reservoirs (for example, Pseudomonas and Sphingobacterium). Furthermore, our results clearly show that some of the seafoodaffiliated OTUs were also present in large numbers on diced bacon (Figure 2) and were responsible for the comparative increase in the bacterial richness of these samples (ca. 20\%; see Figure 1a). As diced bacon is pretreated with brine prior to packaging, we attributed the presence of these seafood-affiliated OTUs to seasalt contamination.

\section{Environmental psychrotrophic bacteria were highly} prevalent in the general core community

The general core community comprised 66 OTUs, which likely originated from contamination by skin or hide bacteria (Staphylococcus), as well as those indicative of contamination by soil or water bacteria (Acinetobacter, Pseudomonas and Janthinobacterium). A large proportion of the core community was also made of OTUs affiliated with environmental Firmicutes, either associated with water or with plants and plant-derived animal feed (Vagococcus, Carnobacterium, Lactobacillus and Leuconostoc). We observed that general core OTUs were more abundant in fresh samples (Supplementary Figure S6). In particular, EBP0162, which was assigned to Brochothrix thermosphacta, a well-known agent of food spoilage (Borch et al., 1996; Jaffrès et al., 2011; Macé et al., 2013), was the most ubiquitous and abundant OTU. Word-occurrence analyses for these general core bacteria (Supplementary File S5) highlighted aspects of their ecologies that are relevant to understanding meat and seafood spoilage, namely that they are associated with water/wastewater and soil/plant reservoirs and that they tend to be psychrotrophs (that is mesophilic species capable of surviving or even thriving in a cold environment).

In summary, our $T_{0}$ results show that the microbiota found on fresh foods are formed by two types of contamination: (1) contamination by animal microbiota, which are product specific but occur at rather low levels, and (2) contamination by bacteria with environmental origins (water, in particular), which are more abundant and form the general core community.

Co-occurrence patterns reveal a microbial community shift between fresh food and spoiled food

There was a generalized fivefold reduction in OTU richness in spoiled food versus fresh food (Figure 1). This result was not entirely unexpected as bacterial concentration on $T_{\mathrm{S}}$ samples was at least $4 \log _{10}$ (c.f.u. $\mathrm{g}^{-1}$ ) higher, and this microbiota was dominated by fewer OTUs, many of them being affiliated to known spoilage-causing species (see for reviews 
Labadie, 1999; Jackson et al., 2001; Gram and Dalgaard, 2002; Nychas et al., 2008 and references therein). We observed that $22 \%$ of the $T_{\mathrm{S}}$ microbiota (25 of 113 OTUs) was made up of rare OTUs that were present at very low abundances in only one or two samples. We thus focused our analysis on the more common and relevant members of the $T_{\mathrm{S}}$ microbiota (ca. 85 OTUs). In contrast to the $T_{0}$ community, the $T_{\mathrm{S}}$ community showed greater differences in OTU prevalence across food types. For this reason, it was challenging to compare the $T_{0}$ and $T_{\mathrm{S}}$ communities using prevalence data only. To circumvent this difficulty, we characterized OTU co-occurrence and attempted to determine whether specific combinations of OTUs were associated with one or several food types (Figure 4). This analysis showed that the average degree of co-occurrence between each pair of $T_{\mathrm{S}}$ OTUs was indeed significant $(46.5 \%)$. However, we also detected several modules of very frequently co-occurring OTUs whose structures mirrored the core and productspecific communities observed at $T_{0}$ (Figure 4 , see also Supplementary File S7 for a detailed description of these OTUs). Next, we compared frequently co-occurring OTU groups to the OTUs recovered from $T_{0}$ communities. At first glance, the OTU cooccurrence network suggests that each food type retained the specific set of microbes it had at $T_{0}$. However, looking a bit closer, it is clear that the vast majority of the $T_{\mathrm{S}}$ OTUs (ca. $60 \%$ ) arose from core $T_{0}$ OTUs and, in particular, from the $T_{0}$ general core community (Supplementary File S8). We have

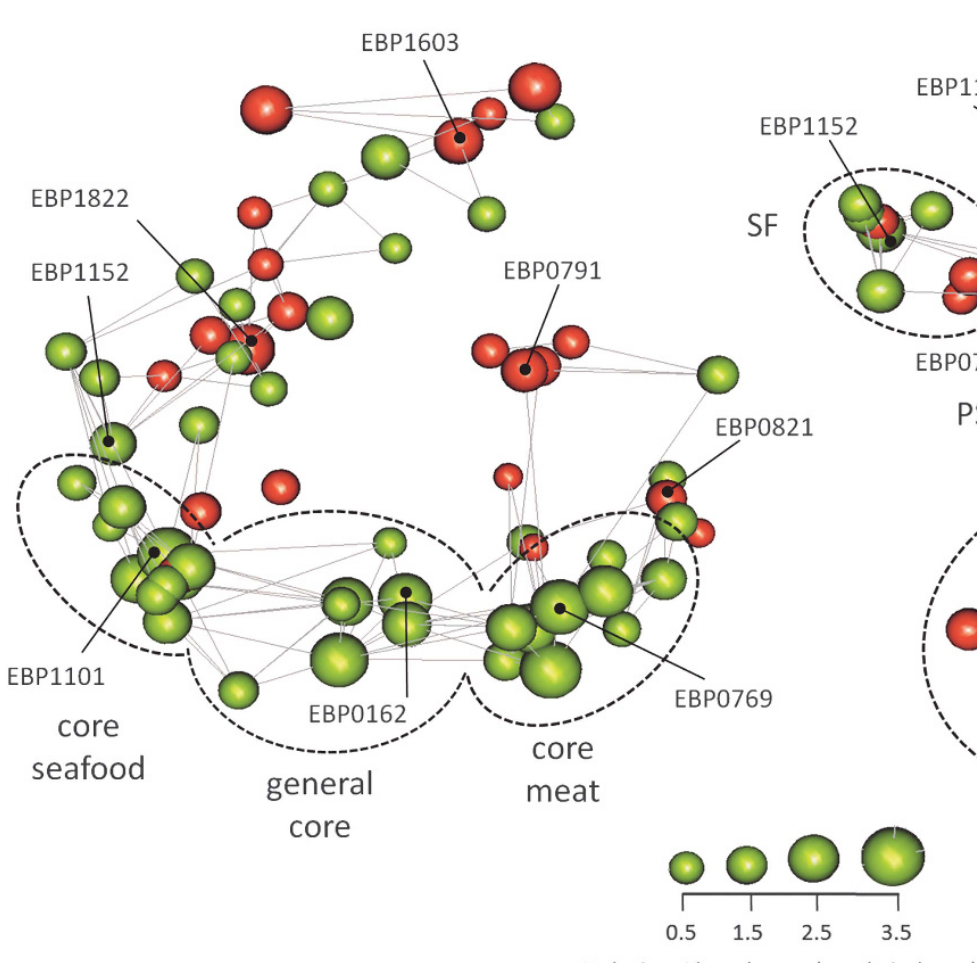

Relative Abundance (reads in $\log _{10}$ )

b

\section{EBP0769}


already underscored the prevalence of psychrotrophs within the $T_{0}$ general core community and, to some extent, the $T_{0}$ core seafood community. These results thus corroborate earlier findings (Rudi et al., 2004; Ercolini et al., 2009) and show that low storage temperatures act as one of the main selective pressures on these microbiota. Indeed, very few OTUs from the product-specific $T_{0}$ clusters and the $T_{0}$ core meat cluster, which contained contaminating bacteria from animal sources, were found among the spoilage microbiota. This result is also echoing recent studies, which highlighted the need to change plating analytical techniques toward the use of low cultivation temperatures to better characterize meat and seafood spoilage bacterial species (Kato et al., 2000; Sakala et al., 2002; Rahkila et al., 2012; Pothakos et al. 2014).

Packaging and nutritional aspects of the food matrix act as strong selective factors affecting the final composition of spoilage microbiota

Other factors also appear to dynamically shape $T_{S}$ communities, as a very small fraction (ca. 10\%) of $T_{0}$ general core OTUs that were still present across all spoiled food types (Supplementary File S8). Among these were EBP0162, being both the most prevalent and abundant OTU found at $T_{0}$, but also OTUs assigned to Carnobacterium and Serratia/Hafnia species that are ubiquitous in cold water and soil, and able to survive in environments with extremely high levels of $\mathrm{CO}_{2}$ (Leisner et al., 2007; Nicholson et al., 2013; Petersen and Tisa, 2013; Schuerger et al., 2013). This fact is particularly relevant because most of the food items in this study were in packages containing high levels of $\mathrm{CO}_{2}$ (Table 1); such modified-atmosphere packaging techniques have been correlated with a strong inhibition of aerobic spoilage organisms (Gill and Tan, 1980). Indeed, $\sim 30 \%$ of the $T_{0}$ general core community was composed of such organisms (Pseudomonas, Acinetobacter and Staphylococcus), but these were practically absent from the $T_{\mathrm{S}}$ microbiota. In addition to supporting the idea that packaging exerts selective pressure, our data also suggest that the properties of food products, perhaps their nutritional matrices, select for particular OTU communities; these selective pressures may split the $T_{0}$ general core community into core meat and seafood communities or even result in the product-specific co-occurrence of $T_{\mathrm{S}}$ OTU groups (Figure 4 and Supplementary File S8). In particular, there was a clear phylum-level differentiation among meat (Firmicutes) and seafood (Proteobacteria) OTUs which suggests, as already expressed in previous opinions (Labadie, 1999; Gram and Dalgaard, 2002), that functional structuring is occurring and that perhaps the microbiota have nutritional needs that correspond to different food types.

To test this idea, we examined how OTU abundance changed between $T_{0}$ and $T_{\mathrm{S}}$ in each food type using weighted UNIFRAC distances (Figure 5). Bacterial assemblages described in beef and veal samples were the most stable across time, as the relative abundance of OTUs at $T_{0}$ was similar to that at $T_{\mathrm{s}}$. In both food products, bacterial communities were dominated by a set of five dominant OTUs, two of which, EBP0794 and EBP0745 (Supplementary File S7), were not described until now with such ascendency over the remaining OTUs. In contrast, OTU abundances on diced bacon and poultry sausages changed much more dramatically, a

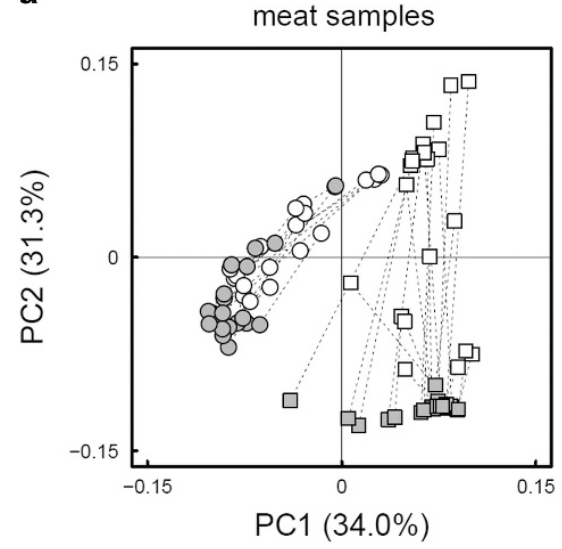

b

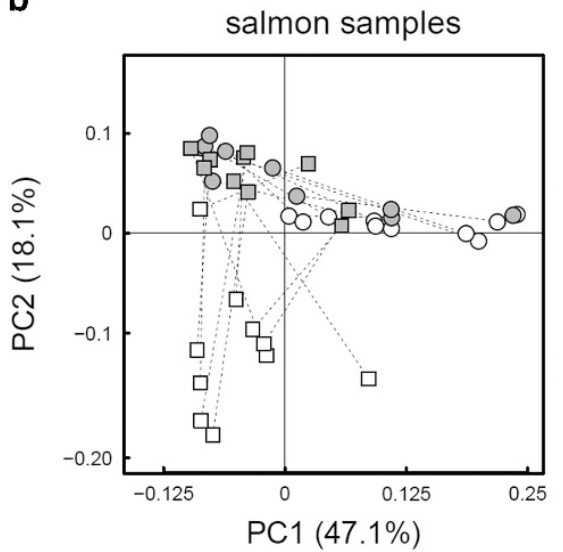

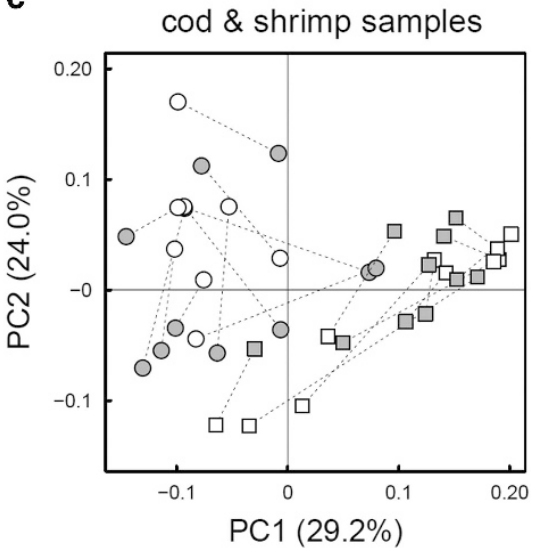

Figure 5 Comparative analysis of the changes that occurred in bacterial communities between $T_{0}$ and $T_{\mathrm{S}}$. In this analysis, the abundance of each of the 113 OTUs in the $T_{\mathrm{S}}$ data set was extracted from the $T_{0}$ data set; their relative abundances at $T_{0}$ and $T_{\mathrm{S}}$ were then compared to illustrate converging or diverging trajectories of abundance among spoiled samples of the same food type. The plots show the results of the principal coordinates analysis (PCoA) that used pairwise weighted UNIFRAC distances for each food type at $T_{0}$ (white symbols) and $T_{\mathrm{S}}$ (gray symbols). Samples that came from the same batch of food are connected with a thin striped line. Food types were analyzed in three separate plots and independent UNIFRAC analysis (a-c) for clarity. (a) Meat samples. Diced bacon and poultry sausages samples (squares); ground beef and ground veal samples (circles). (b) Salmon samples. Salmon fillet samples (squares); smoked salmon samples (circles). (c) Cod and shrimp samples. Cod fillet samples (squares); cooked shrimp samples (circles). The proportion of variance explained by each axis is shown. 
seemingly as a result of selection for halotolerant species. The high levels of salt and small amounts of glucose in these foods (footnote of Table 1) appear to have selected for these OTUs, which are at low abundance in $T_{0}$ communities. The changes seen in seafood spoilage communities were more complex than those seen in meat-spoilage communities. First of all, there was a high degree of intersample variability in the abundance of $T_{\mathrm{S}}$-affiliated OTUs in fresh seafood samples, which led to a scattering of $T_{0}$ samples in Figure 5. Nevertheless, spoiled cod fillet, salmon fillet and smoked salmon samples show clear convergence in their dominant OTUs. It is worth noting that the microbiota of $T_{\mathrm{S}}$ smoked salmon and salmon fillet also overlapped strongly, although, as mentioned above, the smoking process affected both the richness and abundance of the $T_{0}$ microbiota. These results are in accordance with previous works on the microbial ecology on spoiled salmon and smoked salmon (Leroi et al., 1998; Emborg et al., 2002; Olofson et al., 2007; Macé et al., 2013), which if they are compared, reveal how packaging and food matrices may dynamically shape microbiota by favoring a specific set of dominant spoilage species. Surprisingly, $T_{0}$ cooked shrimp samples followed distinct trajectories, and different samples were dominated by several types of spoilage microbiota at $T_{\mathrm{s}}$. We have identified two possible explanations. First, the most abundant OTU in $T_{0}$ shrimp (EBP1918) is presumably an endosymbiont that is present at very low frequencies in the $T_{\mathrm{S}}$ samples. Second, the abundant $T_{\mathrm{S}}$ OTUs in shrimp originate from shrimp-specific OTUs (including potentially pathogenic bacteria, see below) that are barely detected in the $T_{0}$ samples.

Unexpected and varied subdominant $T_{S}$ communities on spoiled seafood samples

With a few exceptions, the $T_{\mathrm{S}}$ product-specific OTUs formed subdominant communities $(<5 \%$ of relative abundance) and were far richer on seafood than on meat. It was difficult to find commonalities in the ecologies of all these product-specific OTUs. However, we mainly observed two types of situations. First, the identity of these OTUs depended on the growth patterns of specific $T_{0}$ core community members. For example, Propionibacterium acnes (EBP1152), the only Actinobacteria that was found among the various $T_{\mathrm{S}}$ microbiota, was the third most prevalent among all $T_{0}$ samples (Supplementary File S6). However, at $T_{\mathrm{S}}$ it had become salmon-fillet specific, which suggests, once again, the selective influence that a given food matrix might exert. Second, $T_{\mathrm{S}}$ product-specific OTUs resulted from the growth of species already identified among the $T_{0}$ product-specific OTU clusters. Spoiled cod fillet contained the greatest number of these subdominant, product-specific OTUs. Analyses of these varied spoilage communities also revealed three key results. First, we detected OTUs that are associated with potential pathogens of fish and crustaceans (see specific labeling in Supplementary File S7). Some of these OTUs are even dominant in spoiled shrimp samples. Second, we identified undescribed taxa. The most striking example was OTU EBP1822, whose presence in $T_{0}$ samples was discussed above; it was the most dominant species in $70 \%$ of spoiled cod fillet samples (Figure 4 and Supplementary File S7), is affiliated with the Hados.Sed.Eubac.3 family in the SILVA database, and possibly represents a new family clade within the order Fusobacteriales. It is not yet known if this species can be cultivated under laboratory conditions, which would give us the opportunity to further characterize its role in spoilage. In particular, it has been previously shown (Dalgaard, 1998) that spoilage of cod stored at cold temperature and under modified atmosphere is quantitatively correlated to the concentration of Photobacterium phosphoreum (EPB1101 in our study, an OTU being the second most abundant after EBP1822). Thus, it remains to be determined how these two dominant OTUs interact and participate individually, alternatively or in synergy into cod spoilage. Third, we observed the presence (and thus the effective growth) of $T_{0}$ OTUs assigned to Hydrogenophilus hirshii (EBP0720) and Geobacillus debilis (EBP0713) on spoiled salmon fillet. This observation was quite surprising given that these organisms are thermophilic and are typically found in geothermal habitats (Stohr et al., 2001; Banat et al., 2004); however, it may be that they occur in salmon aquacultures, even if the environment is cold (Marchant et al., 2002), and that they have a greater growth capacity than previously described.

\section{Conclusions}

In conclusion, our study significantly contributes to an understanding of the complex changes seen in spoilage microbiota found on perishable food of animal origin. We were able to suggest reservoirs of spoilage bacteria and infer the impact of both processing (low storage temperatures and packaging) and food properties on these communities. This study is the first to show that core microbial communities exist on both meat and seafood products and that very specific groups of psychrothrophic bacteria, most likely originating from water reservoirs, are key components of these assemblages. It seems probable that refrigerated storage generates suitable conditions under which these bacteria flourish. Moreover, we identified novel species that may be involved in spoilage (for example, in cod) and observed unanticipated assemblages of dominant species (for example, in beef and veal). We have shown that food spoilage remains a complex phenomenon that also involves abiotic factors. The next step is to tease apart the functional interactions that occur between dominant and subdominant species. An important question for future study is 
if the core communities form functional assemblages or if only a subset of them are involved in the spoilage process. We are convinced that our results will allow food scientists to artificially reconstruct spoilage microbiota and thus test such functional hypotheses using metagenomic and metatranscriptomic analyses.

\section{Conflict of Interest}

The authors declare no conflict of interest.

\section{Acknowledgements}

This study and our consortium of laboratories, which use the project acronym ECOBIOPRO and are coordinated by $\mathrm{MZ}$ and M-CC-V, were supported by a public grant from the French Agence Nationale de la Recherche (ANR) within the context of the ALIA (Food Research) program (reference ANR-10-ALIA-018-02). Our consortium is also part of FLOREPRO, a French technological network (RMT) coordinated by SC and CF that aims to provide knowledge about the use of food biopreservative cultures and that provided the framework for the current project. We thank VALORIAL and AQUIMER, two French organizations that promote the food industry, for supporting this project, providing advice and helping to disseminate our results to the French food industry. We are also grateful to the INRA MIGALE bioinformatics platform (htpp://migale.jouy. inra.fr) for providing computational resources and data storage. Finally, we would like to acknowledge the EUROFINS high-throughput sequencing unit for fruitful discussions and advice regarding implementation of the pyrosequencing strategy.

\section{References}

Argyri AA, Doulgeraki AI, Blana VA, Panagou E, Nychas GJE. (2001). Potential of simple HPLC-based approach for the identification of the spoilage status of minced beef stored at various temperature and packaging systems. Int J Food Microbiol 150: 25-33.

Baele M, Vancanneyt M, Devriese LA, Lefebvre K, Swings J, Haesebrouck F. (2003). Lactobacillus ingluviei sp. nov., isolated from the intestinal tract of pigeons. Int J Syst Evol Microbiol 53: 133-136.

Banat IM, Marchant R, Rahman TJ. (2004). Geobacillus debilis sp. nov., a novel obligately thermophilic bacterium isolated from a cool soil environment, and reassignment of Bacillus pallidus to Geobacillus pallidus comb. nov. Int J Syst Evol Microbiol 54: 2197-2201.

Barott KL, Rodriguez-Brito B, Janouskovec J, Marhaver KL, Smith JE, Keeling P et al. (2011). Microbial diversity associated with four functional groups of benthic reef algae and the reef-building coral Montastraea annularis. Environ Microbiol 13: 1192-1204.

Borch E, Kant-Muermans ML, Blixt Y. (1996). Bacterial spoilage of meat and cured meat products. Int J Food Microbiol 33: 103-120.

Boziaris IS, Stamatiou AP, Nychas GJE. (2012). Microbial aspects and shelf life of processed seafood products. J Sci Food Agric 93: 1184-1190.
Broekaert K, Heyndrickx M, Herman L, Devlieghere F, Vlaemynck G. (2011). Seafood quality analysis: Molecular identification of dominant microbiota after ice storage on several general growth media. Food Microbiol 28: 1162-1169.

Broekaert K, Heyndrickx M, Herman L, Devlieghere F, Vlaemynck G. (2013). Molecular identification of the microbiota of peeled and unpeeled brown shrimp (Crangon crangon) during storage on ice and at 7.5 degrees C. Food Microbiol 36: 123-134.

Caporaso JG, Kuczynski J, Stombaugh J, Bittinger K, Bushman FD, Costello EK et al. (2010). QIIME allows analysis of high-throughput community sequencing data. Nat Methods 7: 335-336.

Chao A. (1984). Nonparametric estimation of the number of classes in a population. Scand J Stat 11: 783-791.

Cole JR, Wang Q, Cardenas E, Fish J, Chai B, Farris RJ et al. (2009). The Ribosomal Database Project: improved alignments and new tools for rRNA analysis. Nucleic Acids Res 37: D141-D145.

De Filippis F, La Storia A, Villani F, Ercolini D. (2013). Exploring the sources of bacterial spoilers in beefsteaks by culture-independent high-throughput sequencing. PLoS One 8: e70222.

Dalgaard P. (1995). Qualitative and quantitative characterization of spoilage bacteria from packed fish. Int J Food Micriobiol 19: 283-294.

Dalgaard P. (1998). Methods to determine the freshness of fish in research and industry. In Evaluation of fish freshness 166-174.

Dixon P. (2003). VEGAN, a package of $R$ functions for community ecology. J Veg Sci 14: 927-930.

Doulgeraki AI, Ercolini D, Villani F, Nychas GJ. (2012). Spoilage microbiota associated to the storage of raw meat in different conditions. Int J Food Microbiol 157: 130-141.

Emborg J, Laursen BG, Rathjen T, Dalgaard P. (2002). Microbial spoilage and formation of biogenic amines in fresh and thawed modified atmosphere-packed salmon (Salmo salar) at 2 degreesC. J Appl Microbiol 92: 790-799.

EUFOMA (2014). The EU Fish market. http://ec.europa.eu/fisheries/market-observatory/documents/ 10157/bf18cf2c-1b33-440d-8870-e05b2644b58b.

Ercolini D, Russo F, Torrieri E, Masi P, Villani F. (2006). Changes in the spoilage-related microbiota of beef during refrigerated storage under different packaging conditions. Appl Environ Microbiol 72: 4663-4671.

Ercolini D, Russo F, Nasi A, Ferranti P, Villani F. (2009). Mesophilic and psychrotrophic bacteria from meat and their spoilage potential in vitro and in beef. Appl Environ Microbiol 75: 1990-2001.

Funaro CF, Kronauer DJ, Moreau CS, Goldman-Huertas B, Pierce NE, Russell JA. (2011). Army ants harbor a host-specific clade of Entomoplasmatales bacteria. Appl Environ Microbiol 77: 346-350.

Gram L, Huss HH. (1996). Microbiological spoilage of fish and fish products. Int J Food Microbiol. 33: 121-137.

Gill CO, Tan KH. (1980). Effect of Carbon dioxide on growth of meat spoilage bacteria. Appl Environ Microbiol 39: 317-319.

Gouy M, Guindon S, Gascuel O. (2010). SeaView version 4: a multiplatform graphical user interface for sequence alignment and phylogenetic tree building. Mol Biol Evol 27: 221-224.

Gram L, Dalgaard P. (2002). Fish spoilage bacteriaproblems and solutions. Curr Opin Biotechnol 13: 262-266. 
Guindon Sp, Dufayard J-Fo, Lefort V, Anisimova M, Hordijk W, Gascuel O. (2010). New algorithms and methods to estimate maximum-likelihood phylogenies: assessing the performance of PhyML 3.0. Syst Biol 59: 307-321.

Guri M, Durand L, Cueff-Gauchard V, Zbinden M, Crassous P, Shillito B et al. (2012). Acquisition of epibiotic bacteria along the life cycle of the hydrothermal shrimp Rimicaris exoculata. ISME J 6: 597-609.

Hamady M, Lozupone C, Knight R. (2010). Fast UniFrac: facilitating high-throughput phylogenetic analyses of microbial communities including analysis of pyrosequencing and PhyloChip data. ISME J 4: 17-27.

Hansen GH, Olafsen JA. (1999). Bacterial interactions in eraly life stages of marine cold water fish. Microb Ecol 38: 1-26.

Hovda MB, Lunestad BT, Sivertsvik M, Rosnes JT. (2007). Characterisation of the bacterial flora of modified atmosphere packaged farmed Atlantic cod (Gadus morhua) by PCR-DGGE of conserved 16S rRNA gene regions. Int J Food Microbiol 117: 68-75.

Ismail SAS, Deak T, Abd El-Rahman HA, Yassien MAM, Beuchat LR. (2000). Presence and changes in population of yeasts on raw and processed poultry products stored at refrigerated temperature. Int J Food Microbiol 62: 113-121.

Jaffrès E, Sohier D, Pilet MF, Prévost H, Joffraud JJ, Dousset X. (2009). Study of the bacterial ecosystem in tropical cooked and peeled shrimps using a polyphasic approach. Int J Food Microbiol 131: 20-29.

Jaffrès E, Lalanne V, Mace S, Cornet J, Cardinal M, Serot T et al. (2011). Sensory characteristics of spoilage and volatile compounds associated with bacteria isolated from cooked and peeled tropical shrimps using SPMEGC-MS analysis. Int J Food Microbiol 147: 195-202.

Fredrickson J, Romine MF, Beliaev AF, Auchtung JM, Driscoll ME, Gardner TS et al. (2008). Towards environmental systems biology of Shewanella. Nat Rev Microbiol 6: 592-603.

Jackson TC, Marshall DL, Acuff GR, Dickson JS. (2001). Meat, poultry and seafood. In Doyle MP et al. (ed) Food Microbiology: Fundamentals and Frontiers, 2nd edn. ASM press: Washington, D.C., USA 91-109.

Jami E, Israel A, Kotser A, Mizrahi I. (2013). Exploring the bovine rumen bacterial community from birth to adulthood. ISME J 7: 1069-1079.

Jiang Y, Gao F, Xu X, Ye K, Zhou G. (2011). Changes in the composition of the bacterial flora on tray-packaged pork during chilled storage analyzed by PCR-DGGE and real-time PCR. J Food Sci 76: M27-M33.

Joffraud JJ, Cardinal M, Cornet J, Chasles JS, Leon S, Gigout $\mathrm{F}$ et al. (2006). Effect of bacterial interactions on the spoilage of cold-smoked salmon. Int J Food Microbiol 112: 51-61.

Kanerva M. (2013). Meat consumption in Europe. Issues, trends and debateshttp://www.academia.edu/ 2486553/Meat_consumption_in_Europe_Issues_trends_ and debates).

Kato Y, Sakala RM, Hayashidani H, Kiuchi A, Kaneuchi C, Ogawa M. (2000). Lactobacillus algidus sp. nov., a psychrophilic lactic acid bacterium isolated from vacuum-packaged refrigerated beef. Int J Syst Evol Microbiol 50: 1143-1149.

Kim OS, Cho YJ, Lee K, Yoon SH, Kim M, Na $\mathrm{H}$ et al. (2012). Introducing EzTaxon-e: a prokaryotic 16S rRNA gene sequence database with phylotypes that represent uncultured species. Int J Syst Evol Microbiol 62: $716-721$
Kostanjsek R, Strus J, Avgustin G. (2007). "Candidatus Bacilloplasma," a novel lineage of Mollicutes associated with the hindgut wall of the terrestrial isopod Porcellio scaber (Crustacea: Isopoda). Appl Environ Microbiol 73: 5566-5573.

Labadie J. (1999). Consequences of packaging on bacterial growth. Meat is an ecological niche. Meat Sci 52: 299-305.

Lane DJ. (1991). 16S/23S rRNA sequencing. In: Stackebrandt E, Goodfellow M (eds) Nucleic Acid Techniques in Bacterial Systematics. John Wiley and Sons: New York, NY, USA, pp 115-175.

Leisner JJ, Laursen BG, Prevost H, Drider D, Dalgaard P. (2007). Carnobacterium: positive and negative effects in the environment and in foods. FEMS Microbiol Rev 31: 592-613.

Lemon KP, Klepac-Ceraj V, Schiffer HK, Brodie EL, Lynch SV, Kolter R. (2010). Comparative analysis of the bacterial microbiota of the human Nostril and Oropharynx. MBio 1: e00129-10.

Leroi F, Joffraud JJ, Chevalier F, Cardinal M. (1998). Study of the microbial ecology of cold-smoked salmon during storage at $8^{\circ} \mathrm{C}$. Int J Food Microbiol 39: 111-121.

Li H, Handsaker B, Wysoker A, Fennell T, Ruan J, Homer N et al. (2009). The Sequence Alignment/Map format and SAMtools. Bioinformatics 25: 2078-2079.

Li W, Godzik A. (2006). Cd-hit: a fast program for clustering and comparing large sets of protein or nucleotide sequences. Bioinformatics 22: 1658-1659.

Lu J, Sanchez S, Hofacre C, Maurer JJ, Harmon BG, Lee MD. (2003). Evaluation of broiler litter with reference to the microbial composition as assessed by using $16 \mathrm{~S}$ rRNA and functional gene markers. Appl Environ Microbiol 69: 901-908.

Lu XM, Lu PZ, Zhang H. (2013). Bacterial communities in manures of piglets and adult pigs bred with different feeds revealed by $16 \mathrm{~S}$ rDNA 454 pyrosequencing. Appl Microbiol Biotechnol. 98: 2657-2665.

Lun Z-R, Wang Q-P, Chen X-G, Li A-X, Zhu X-Q. (2007). Streptococcus suis: an emerging zoonotic pathogen. Lancet Infect Dis 7: 201-209.

Macé S, Joffraud JJ, Cardinal M, Malcheva M, Cornet J, Lalanne V et al. (2013). Evaluation of the spoilage potential of bacteria isolated from spoiled raw salmon (Salmo salar) fillets stored under modified atmosphere packaging. Int J Food Microbiol 160: 227-238.

Marchant R, Banat IM, Rahman TJ, Berzano M. (2002). What are high-temperature bacteria doing in cold environments? Trends Microbiol 10: 120-121.

Matamoros S, Leroi F, Cardinal M, Gigout F, Kasbi Chadli F, Cornet J et al. (2009). Psychrotrophic lactic acid bacteria used to improve the safety and quality of vacuum-packaged cooked and peeled tropical shrimp and cold-smoked salmon. J Food Prot 72: 365-374.

Mejlhom O, Bøknaes N, Dalgaard P. (2005). Shelf life and safety aspects of chilled cooked and peeled shrimps (Pandalus borealis) in modified atmosphere packaging. J Appl Microbiol 99: 66-76.

Munoz R, Yarza P, Ludwig W, Euzeby J, Amann R, Schleifer KH et al. (2011). Release LTPs104 of the AllSpecies Living Tree. Syst Appl Microbiol 34: 169-170.

Nechitaylo TY, Timmis KN, Golyshin PN. (2009). 'Candidatus Lumbricincola', a novel lineage of uncultured Mollicutes from earthworms of family Lumbricidae. Environ Microbiol 11: 1016-1026.

NF V01-003. (2010). Food safety - Guidelines for implementing microbiological durability tests - Chilled 
perishable and highly perishable foodstuffs. http:// www.boutique.afnor.org/norme/nf-v01-003/hygienedes-aliments-lignes-directrices-pour-la-realisationde-tests-de-vieillissement-microbiologique-alimentsperissables-/article/675928/fa163631.

Nicholson WL, Krivushin K, Gilichinsky D, Schuerger AC. (2013). Growth of Carnobacterium spp. from permafrost under low pressure, temperature, and anoxic atmosphere has implications for Earth microbes on Mars. Proc Natl Acad Sci USA 110: 666-671.

Nieminen TT, Koskinen K, Laine P, Hultman J, Sade E, Paulin L et al. (2012). Comparison of microbial communities in marinated and unmarinated broiler meat by metagenomics. Int J Food Microbiol 157: 142-149.

Nielsen DS, Jacobsen T, Jespersen L, Granly Koch A, Arneborg N. (2008). Occurence of growth yeasts in processed meat products - Implications for potential spoilage. Meat Sci 80: 919-926.

Nychas G-JE, Skandamis PN, Tassou CC, Koutsoumanis KP. (2008). Meat spoilage during distribution. Meat Sci 78: 77-89.

Olofsson TC, Ahrne S, Molin G. (2007). The bacterial flora of vacuum-packed cold-smoked salmon stored at 7 degrees C, identified by direct $16 \mathrm{~S}$ rRNA gene analysis and pure culture technique. J Appl Microbiol 103: 109-119.

Olsson C, Ahrne S, Pettersson B, Molin G. (2003). The bacterial flora of fresh and chill-stored pork: analysis by cloning and sequencing of $16 \mathrm{~S}$ rRNA genes. Int J Food Microbiol 83: 245-252.

Patsias A, Chouliara I, Badeka A, Savvaidis IN, Kontonimas MG. (2006). Shelf-life of a chilled precooked chicken product stored in air and under modified atmospheres: microbiological, chemical, sensory attributes. Food Microbiol 23: 423-429.

Petersen LM, Tisa LS. (2013). Friend or foe? A review of the mechanisms that drive Serratia towards diverse lifestyles. Can J Microbiol 59: 627-640.

Pothakos V, Snauvaert C, De Vos P, Huys G, Devlieghere F. (2014). Psychrothrophic members of Leuconostoc gasicomitatum, Leuconostoc gelidum and Lactococcus piscium dominate at the end of shelf-life in packaged and chilled-stored food products in Belgium. Food Microbiol 39: 61-67.

Pruesse E, Peplies J, Glockner FO. (2012). SINA: accurate high-throughput multiple sequence alignment of ribosomal RNA genes. Bioinformatics 28: 1823-1829.

Quast C, Pruesse E, Yilmaz P, Gerken J, Schweer T, Yarza P et al. (2012). The SILVA ribosomal RNA gene database project: improved data processing and web-based tools. Nucleic Acids Res 41: D590-D596.

$\mathrm{R}$ Development Core Team (2010). R: a language and environment for statistical computing. R Foundation for Statistical Computing: Vienna, Austria.

Rahkila R, Nieminen T, Johansson P, Sade E, Bjorkroth J. (2012). Characterization and evaluation of the spoilage potential of Lactococcus piscium isolates from modified atmosphere packaged meat. Int $J$ Food Microbiol 156: 50-59.

Reynisson E, Lauzon HL, Magnusson H, Jonsdottir R, Olafsdottir G, Marteinsson V et al. (2009). Bacterial composition and succession during storage of North-Atlantic cod (Gadus morhua) at superchilled temperatures. BMC Microbiol 9: 250.
Robidart JC, Bench SR, Feldman RA, Novoradovsky A, Podell SB, Gaasterland T et al. (2008). Metabolic versatility of the Riftia pachyptila endosymbiont revealed through metagenomics. Environ Microbiol 10: 727-737.

Rodrigues DF, Ivanova N, He Z, Huebner M, Zhou J, Tiedje JM. (2008). Architecture of thermal adaptation in an Exiguobacterium sibiricum strain isolated from 3 million year old permafrost: a genome and transcriptome approach. BMC Genomics 9: 547.

Roeselers G, Mittge EK, Stephens WZ, Parichy DM, Cavanaugh CM, Guillemin K et al. (2011). Evidence for a core gut microbiota in the zebrafish. ISME J 5: 1595-1608.

Rudi K, Maugeste T, Hannevick SE, Nissen H. (2004). Explorative multivariate analyses of 16S rRNA gene data from microbial communities in modifiedatmosphere-packed salmon and coalfish. Appl Environ Microbiol 70: 5010-5018.

Russell JA, Moreau CS, Goldman-Huertas B, Fujiwara M, Lohman DJ, Pierce NE. (2009). Bacterial gut symbionts are tightly linked with the evolution of herbivory in ants. Proc Natl Acad Sci USA 106: 21236-21241.

Sade E, Murros A, Bjorkroth J. (2013). Predominant enterobacteria on modified-atmosphere packaged meat and poultry. Food Microbiol 34: 252-258.

Sakala RM, Kato Y, Hayashidani H, Murakami M, Kaneuchi C, Ogawa M. (2002). Lactobacillus fuchuensis sp. nov., isolated from vacuum-packaged refrigerated beef. Int J Syst Evol Microbiol 52: 1151-1154.

Sammon JW. (1969). A nonlinear mapping for data structure analysis. IEEE Trans Comput 18: 401-402.

Schommer NN, Gallo RL. (2013). Structure and function of the human skin microbiome. Trends Microbiol 21: $660-668$.

Schuerger AC, Ulrich R, Berry BJ, Nicholson WL. (2013). Growth of Serratia liquefaciens under 7 mbar, 0 degrees C, and CO2-enriched anoxic atmospheres. Astrobiology 13: 115-131.

Stohr R, Waberski A, Liesack W, Volker H, Wehmeyer U, Thomm M. (2001). Hydrogenophilus hirschii sp. nov., a novel thermophilic hydrogen-oxidizing beta-proteobacterium isolated from Yellowstone National Park. Int J Syst Evol Microbiol 51: 481-488.

Sullam KE, Essinger SD, Lozupone CA, O'Connor MP, Rosen GL, Knight R et al. (2012). Environmental and ecological factors that shape the gut bacterial communities of fish: a meta-analysis. Mol Ecol 21: 3363-3378.

Suzuki R, Shimodaira H. (2006). Pvclust: an R package for assessing the uncertainty in hierarchical clustering. Bioinformatics 12: 1540-1542.

Venables WN, Ripley BD. (2002). Modern Applied Statistics with $S$, 4th edn Springer: New York, NY, USA.

Wong S, Rawls JF. (2012). Intestinal microbiota composition in fishes is influenced by host ecology and environment. Mol Ecol 21: 3100-3102.

Wright ES, Yilmaz LS, Noguera DR. (2011). DECIPHER, a search-based approach to chimera identification for 16S rRNA sequences. Appl Environ Microbiol 78: 717-725.

Ye L, Zhang T, Wang TT, Fang ZW. (2012). Microbial structures, functions, and metabolic pathways in wastewater treatment bioreactors revealed using high-throughput sequencing. Environ Sci Technol 46: 13244-13252.

Supplementary Information accompanies this paper on The ISME Journal website (http://www.nature.com/ismej) 